\title{
Continued search for the cellular signals that regulate regeneration of dopaminergic neurons in goldfish retina
}

\author{
Janet E. Braisted *, Pamela A. Raymond \\ Department of Anatomy and Cell Biology, 4607 Medical Science II, University of Michigan, Ann Arbor, MI 48109-0616, USA
}

(Accepted 13 July 1993)

Key words: 6-Hydroxydopamine; Tunicamycin; Differentiation; Retina; Photoreceptor; Immunocytochemistry; Goldfish; Retinal regeneration

\begin{abstract}
Intraocular injections of low doses (0.7-1.4 mM estimated intraocular concentration) of 6-hydroxydopamine (6OHDA) selectively destroy dopaminergic neurons in the inner nuclear layer (INL) of goldfish retina, and they never regenerate. However, injection of a higher dose of 6OHDA ( $2.9 \mathrm{mM}$ ) destroys $>30 \%$ (but not all) of the cells in both the INL and the outer nuclear layer (ONL), but within 3 weeks, neurons in both the INL (including dopaminergic neurons) and the ONL regenerate. We hypothesize that the regenerated neurons derive from mitotic rod precursors in the ONL and that damage to the surrounding micro-environment (i.e. destruction of photoreceptors) triggers the regenerative response. To directly test this hypothesis, we selectively ablated $>99 \%$ of dopaminergic neurons (with low doses of $60 \mathrm{ODA}$ ) and up to 55\% of rod photoreceptors (with tunicamycin), and asked whether the dopaminergic neurons regenerated, as evidenced by double immunolabeling with anti-tyrosine hydroxylase and anti-bromodeoxyuridine. After 38 days, the number of bromodeoxyuridine-immunoreactive rod nuclei was increased 2.4-fold compared to controls, but no regenerated dopaminergic neurons were found. These data suggest that although the rate of rod production increases, rod precursors do not alter their normal pathway of development to replace dopaminergic neurons in the INL when damage to the ONL is limited to destruction of rods.
\end{abstract}

\section{INTRODUCTION}

An unfortunate property of the human retina, and mammalian retinas in general, is their lack of regenerative capability. However, a number of other vertebrates including adult urodele amphibians (newts and salamanders), frog tadpoles, embryonic chicks and adult teleost fish possess a remarkable capacity for retinal regeneration ${ }^{19}$. Two distinct modes of retinal regeneration have been described. The most widely known involves the transdifferentiation of retinal pigmented epithelial cells into neuronal progenitor cells, which occurs following complete removal of neural retina in adult urodeles ${ }^{26,27,51}$, tadpoles ${ }^{48}$ and embryonic chicks ${ }^{6,740}$. In juvenile and adult goldfish, the mode of retinal regeneration following its partial removal or neurotoxic destruction involves a population of residual, dividing neuroepithelial cells scattered among photoreceptor nuclei in the outer nuclear layer (ONL) of the neural retina ${ }^{46}$. These cells are called 'rod precursors', because in the intact retina they give rise exclu-

\footnotetext{
*Corresponding author. Fax: (1) (313) 763-1166.
}

sively to rod photoreceptors ${ }^{11,21,23,43,47}$. However, when the retina is damaged rod precursors apparently undergo a change in fate and produce neurons other than rods ${ }^{18,44,46}$.

It has been known for some time that following surgical lesions or chemical ablation of neurons, the goldfish retina will regenerate ${ }^{19,28-30}$. For example, if a small patch of retina is surgically removed, rod precursor cells along the cut edges proliferate, eventually forming a 'blastema' around the perimeter of the wound $^{18}$. During the next couple of weeks, cells in the blastema continue to proliferate and are slowly displaced toward the center of the lesion, leaving in their wake newly regenerated retina. The goldfish retina also regenerates following destruction of neurons with various chemical agents. Intraocular injection of the $\mathrm{Na}^{+} / \mathrm{K}^{+}$ATPase inhibitor, ouabain, destroys virtually all retinal neurons, but they regenerate within a couple of months from scattered clusters of elongated dividing neuroepithelial cells ${ }^{30,46}$, which appear to derive from surviving rod precursors ${ }^{46}$.

We showed recently that complete ablation of neurons in all retinal layers is not a prerequisite for regeneration. Intraocular injection of relatively high 
doses of 6-hydroxydopamine (6OHDA) destroys $>30 \%$ (but not all) of the cells in both the inner nuclear layer (INL) and the ONL ${ }^{4}$. This non-selective cell loss is most likely due to the accumulation of autoxidation products of 6OHDA in the injection solution ${ }^{5}$. Within 3 weeks, regenerated neurons in both the INL and ONL can be detected by labeling with the thymidine analog bromodeoxyuridine (BUdR $)^{4}$. Similarly, Negishi et al. ${ }^{37}$ described the reappearance (and probable regeneration) of dopaminergic neurons approximately 2 months after their destruction with high doses of 6OHDA.

The inner retina cannot be restored following its partial or complete destruction if the ONL is left intact, however. For example, after injection of lower doses of ouabain, only neurons in the inner retina are killed, and they do not regenerate ${ }^{43}$. Similarly, if selective cells in the inner retina are specifically ablated, no regeneration occurs. This was demonstrated in experiments in which suicide transport of propidium iodide inserted into the optic nerve led to the permanent destruction of retinal ganglion cells ${ }^{17}$. In addition, if dopaminergic interplexiform cells (DA IPCs) are selectively ablated with intraocular injections of low doses of $6 \mathrm{OHDA}^{4,34-37}$ or serotonergic neurons with 5,7-dihydroxytryptamine ${ }^{37}$, they do not regenerate.

Taken together, the above data suggest the following hypothesis: when the immediate cellular environment around the rod precursors is disturbed (destruction of rods and/or cones in the ONL), their progeny change fate and differentiate into neurons other than rods $^{44,46}$. To directly test this hypothesis, we specifically ablated DA IPCs in the INL with low doses of 6OHDA, then asked whether they regenerated if photoreceptors, but no other neurons, were also ablated. We chose to ablate photoreceptors with tunicamycin (TM), an antibiotic that selectively inhibits the formation of the asparagine-linked oligosaccharides of glycoproteins ${ }^{10,50}$. In vitro, TM blocks glycosylation of the visual pigment opsin ${ }^{12,14,41}$, incorporation of opsin into rod outer segment membranes ${ }^{12}$, and membrane morphogenesis of rod outer segments ${ }^{14}$. When injected intraocularly in frogs $^{13}$, rabbits ${ }^{15}$, primates ${ }^{15}$ or ground squirrels $^{1}$ at the doses used, TM selectively destroys photoreceptors (usually both rods and cones), without producing pathological effects on other retinal neurons. However, if higher doses are injected, widespread retinal cytotoxicity occurs within 1 week ${ }^{15}$. When injected intraocularly in goldfish ${ }^{33}$, TM has been shown to destroy rod and possibly cone photoreceptors. We estimate the intraocular concentration they used was $0.03 \mathrm{mg} / \mathrm{ml}$. This study also suggested that some damage to inner retinal neurons may occur at this dose, but no comparison of cell numbers before and after TM administration was presented. By combining 6OHDA and TM injections, we hoped to elucidate the cell-cell interactions that regulate the fate of rod precursor cells.

\section{MATERIALS AND METHODS}

Goldfish (Carassius auratus) $3-4 \mathrm{~cm}$ in body length with nasotemporal eye diameters of $3.4-4.5 \mathrm{~mm}$ were purchased from a local pet store. Unless otherwise stated, all chemicals were obtained from Sigma (St. Louis, MO)

\section{Intraocular injections}

\section{6-Hydroxydopamine (6OHDA)}

Fish were anesthetized in $0.2 \%$ tricaine methanesulfonate and placed on the stage of a Wild stereomicroscope. The naso-temporal eye diameter was measured with a caliper, and the ocular volume was estimated by spherical geometry ${ }^{9}$. A slit was made in the nasal sclera at the limbus with a microknife (Tiemann, Plainview, NY), and a 5- $\mu$ l Hamilton microsyringe with a 33-gauge, fixed, blunt-tipped needle was used to inject both eyes with $3 \mathrm{mg} / \mathrm{ml} \mathrm{6-hydroxydopa-}$ mine hydrochloride in $0.9 \%$ saline, with $3 \mathrm{mg} / \mathrm{ml}$ sodium ascorbate (ASC) to retard the buildup of autoxidation products of 60HDA (quinones) ${ }^{25}$. The appropriate injection volume $(0.9-1.7 \mu 1)$ was calculated from the estimated ocular volume to yield an estimated intraocular concentration of $0.14 \mathrm{mg} / \mathrm{ml}(0.7 \mathrm{mM})$. Injections were repeated on the following day. This paradigm destroys DA IPCs without causing non-specific damage that leads to their regenera-

TABLE I

Summary of experiments

\begin{tabular}{llcll}
\hline Experiment & Treatment & $\begin{array}{l}\text { Survival after } \\
\text { treatment (days) }\end{array}$ & $\begin{array}{l}\text { No. retinas } \\
\text { examined }\end{array}$ & Method \\
\hline 1 & untreated & - & 2 & methacrylate sxn \\
& ASC/DMSO & 12 & 3 & methacrylate sxn \\
6OHDA/TM & 12 & 4 & methacrylate sxn \\
methacrylate sxn \\
TM & 12 & 8 & whole mount \\
whole mount \\
whole mount \\
6OHDA/DMSO & 7 & 2 & 4 & whole mount \\
& frozen sxn & frozen sxn \\
\hline
\end{tabular}


tion ${ }^{4}$. Both eyes of control fish were injected on 2 consecutive days with the injection vehicle (ASC).

\section{Tunicamycin (TM)}

One day after the second injection of 6OHDA, both eyes were injected with $0.9-1.7 \mu \mathrm{lof} 0.4 \mathrm{mg} / \mathrm{ml}$ tunicamycin (TM) in dimethylsulfoxide (DMSO). The amount of TM injected was adjusted to yield an estimated intraocular concentration of $0.02 \mathrm{mg} / \mathrm{ml}(24 \mu \mathrm{M})$. This group will be referred to below as 6OHDA/TM. Both eyes of ASC-injected control fish were injected with DMSO (ASC/DMSO). To determine whether DA IPCs were completely destroyed, and to verify that they did not regenerate at the dose of 6OHDA administered, and to control for possible effects of the TM injection vehicle, both eyes of some fish injected with 6OHDA were injected with DMSO (6OHDA/DMSO). To determine whether 6OHDA affected the ability of TM to destroy photoreceptors, both eyes of other fish (not injected with 6OHDA or ASC) were injected with TM.

The right eyes of another group of fish (not injected with 6OHDA or ASC) were injected with TM and the left eyes with DMSO to determine whether rods and/or cones regenerated.

\section{Bromodeoxyuridine (BUdR)}

To determine whether neurons regenerated, fish were injected 4 times at 4-day intervals (beginning 11 days after TM or DMSO injection) with $0.9-1.7 \mu \mathrm{l}$ of $0.4 \mathrm{mM} \mathrm{BUdR}$ in $0.9 \%$ saline (to produce an estimated intraocular concentration of $0.006 \mathrm{mg} / \mathrm{ml}$ or $20 \mu \mathrm{M}$ ). Retinas were examined 15 days later. With this paradigm, only newly generated and regenerated cells would be labeled with BUdR. Since BUdR was not continuously available to dividing cells, it was expected that only a fraction of the cells born after toxin injection would be labeled.

\section{Histology}

Fish were anesthetized in $0.2 \%$ tricaine methanesulfonate and killed by decapitation 12 days after ASC/DMSO, 6OHDA/TM, or TM injection (Table I, Expt. 1). Unless otherwise stated, all steps in this and the following sections were at room temperature $\left(22^{\circ} \mathrm{C}\right)$. Eyes were removed and fixed in $4 \%$ paraformaldehyde $+0.1 \%$ glutaraldehyde $+0.2 \%$ picric acid in $0.1 \mathrm{M}$ phosphate buffer $+5 \%$ sucrose (PBSS). After $30 \mathrm{~min}$, lenses were removed, eyes were bisected along the dorso-ventral axis, fixed for another $30 \mathrm{~min}$, rinsed in PBSS, dehydrated in graded ethanols and embedded in glycol methacrylate (BioRad Polaron Instruments, Cambridge, MA). Radial sections were cut at $3 \mu \mathrm{m}$ on a Sorvall JB-4 microtome, stained with Lee's stain, coverslipped with DPX (BHD Limited, Ballard Schlesinger, New York, NY), and examined on a Leitz Dialux or Aristoplan light microscope. Rod, cone and INL nuclei were counted as described below.

\section{Immunocytochemistry}

To determine whether DA IPCs were completely destroyed by 6OHDA, some fish were killed 7 days after 6OHDA/DMSO injection (Table 1, Expt. 2) at a time when regeneration of DA IPCs should not have occurred ${ }^{4}$. Since rare DA IPCs survived 6OHDA (see Results), some retinas were examined 420 days after 6OHDA) DMSO injection (Table I, Expt. 2) to determine whether these surviving DA IPCs persisted. Retinas were isolated as whole mounts, fixed $1 \mathrm{~h}$ in $4 \%$ paraformaldehyde in PBSS, then rinsed in PBSS. Vitreous was removed by placing retinas photoreceptor-side down on paper, blotting excess buffer and gently brushing the vitreous off with a small brush.

To visualize DA IPCs, retinas were incubated for $30 \mathrm{~min}$ in mouse Vectastain (Vector Laboratories, Burlingame, CA) blocking solution $+0.5 \%$ Triton $\mathrm{X}-100$, then incubated for $48 \mathrm{~h}$ at $4^{\circ} \mathrm{C}$ in a mouse monoclonal anti-tyrosine hydroxylase antibody (Incstar, Stillwater, $\mathrm{MN}$ ), diluted $1: 10,000$ in mouse Vectastain diluent $+0.5 \%$ Triton X-100. After rinsing in $0.1 \mathrm{M}$ phosphate-buffered saline $+0.5 \%$ Triton (PBST), retinas were incubated $2 \mathrm{~h}$ in Vectastain anti-mouse biotinylated antibody $+0.5 \%$ Triton $\mathrm{X}-100+0.1 \%$ sodium azide, rinsed in PBST, and incubated overnight at $4^{\circ} \mathrm{C}$ in avidin-conjugated Texas red (TR) (Vector Laboratories, Burlingame, CA) diluted 1:25 in $10 \mathrm{mM}$ PBS, $\mathrm{pH} 8.0$.

To determine whether DA IPCs had regenerated, 38 days after injection of 6OHDA/DMSO or 6OHDA/TM (Table I, Expt. 2), retinas from fish injected with BUdR were first processed for $\mathrm{TH}$ immunocytochemistry as described above. To visualize BUdR, retinas were rinsed in PBST then soaked for $1 \mathrm{~h}$ in $2 \mathrm{~N} \mathrm{HCl}$ in PBST to denature the DNA and expose the BUdR antigen ${ }^{49}$. After rinsing in PBST, retinas were blocked $30 \mathrm{~min}$ in $20 \%$ normal goat serum (NGS) in $0.1 \mathrm{M}$ PBST $+0.1 \%$ sodium azide (PBSNT) and then incubated at $4^{\circ} \mathrm{C}$ in rat monoclonal anti-BUdR in culture supernatant (Accurate Chemical, Westbury, NY) diluted 1:20 in PBSNT + $1 \%$ NGS. Forty-eight hours later, retinas were rinsed in PBST and incubated overnight at $4^{\circ} \mathrm{C}$ in donkey anti-rat secondary antibody conjugated to fluorescein isothiocyanate (FITC) diluted $1: 20$ in $1 \%$ NGS + PBSNT.

To verify the location of BUdR + nuclei seen in whole mount preparations, some retinas prepared as described above were cryoprotected, frozen in a $2: 1$ mixture of $20 \%$ sucrose:OCT (Miles, Elkhart, IN), and $3 \mu \mathrm{m}$ radial cryosections were collected ${ }^{2}$. The FITC fluorescence survives the freezing procedure.

To determine whether rods and/or cones had regenerated, eyes were enucleated 38 days after injection of DMSO (left eyes) or TM (right eyes) (Table I, Expt. 3) and fixed for $30 \mathrm{~min}$ in $4 \%$ paraformaldehyde in PBSS. Tissue was then cyrosectioned and processed for double-label immunocytochemistry with RET1 and antiBUdR antibodies. RET1 is a mouse monoclonal antibody in ascites fluid produced against goldfish retinal antigens; it recognizes a nuclear antigen $\left(M_{\mathrm{r}}=50-70 \times 10^{3}\right)$ in cones, horizontal cells, some inner nuclear layer neurons, Müller glial cells, and ganglion cells ${ }^{52}$. Therefore, any BUdR $+/$ RET $1+$ double-labeled cells located in the ONL must be cones and any BUdR $+/$ RET - cells are rods or rod precursors; no other types of nuclei are found in the ONL. Immunocytochemistry was performed as described above, with the following alterations: sections were blocked in 20\% NGS in PBSNT then incubated overnight at $4^{\circ} \mathrm{C}$ in mouse monoclonal RET1 (diluted 1:500 in $1 \%$ NGS + PBST). Sections were then incubated for $30 \mathrm{~min}$ in secondary antibody bound to Texas red. To visualize BUdR, the same sections were then soaked in $2 \mathrm{~N} \mathrm{HCl}$ for $30 \mathrm{~min}$ and incubated overnight in anti-BUdR monoclonal antibody. Bound antibody was visualized after $30 \mathrm{~min}$ incubation in secondary antibody bound to FITC.

To avoid cross-reactivity in double-label immunocytochemical preparations, all secondary antibodies (except Vectastain biotinylated antibody) were preabsorbed by the manufacturer (Jackson Immunoresearch, West Grove, PA) against immunoglobulins of the non-corresponding species. Since the tissue was exposed to the Vectastain biotinylated antibody before incubation in the second primary antibody (anti-BUdR), no cross-reactivity should have occurred.

Retinal whole mounts and radial sections were coverslipped with $60 \%$ glycerol in $0.1 \mathrm{M}$ sodium carbonate buffer, with $0.4 \mathrm{mg} / \mathrm{ml}$ $p$-phenylenediamine to retard fluorescent bleaching 24 , and viewed with a Leitz Aristoplan epifluorescent microscope, using narrow band and wide band FITC cubes (Leitz L3 and 13) and a TR cube (Leitz N2.1).

Nuclear counts

\section{Methacrylate sections}

To quantify cell loss at 12 days after ASC/DMSO, 60HDA/TM, or TM injection, the area of maximum rod loss (minimum number of rods) was determined in dorsal and ventral retina of each methacrylate section ( 4 sections per retina) by scanning the entire section. Areas with minimum density of rods were chosen in untreated retinas. Since the density of rods decreases near the retinal margin ${ }^{31}$ (Braisted and Raymond, unpublished observations), counts were not made within $0.5 \mathrm{~mm}$ of the retinal margin. The selected areas were then centered in the field of view at $1563 \times$ and the number of rods, 

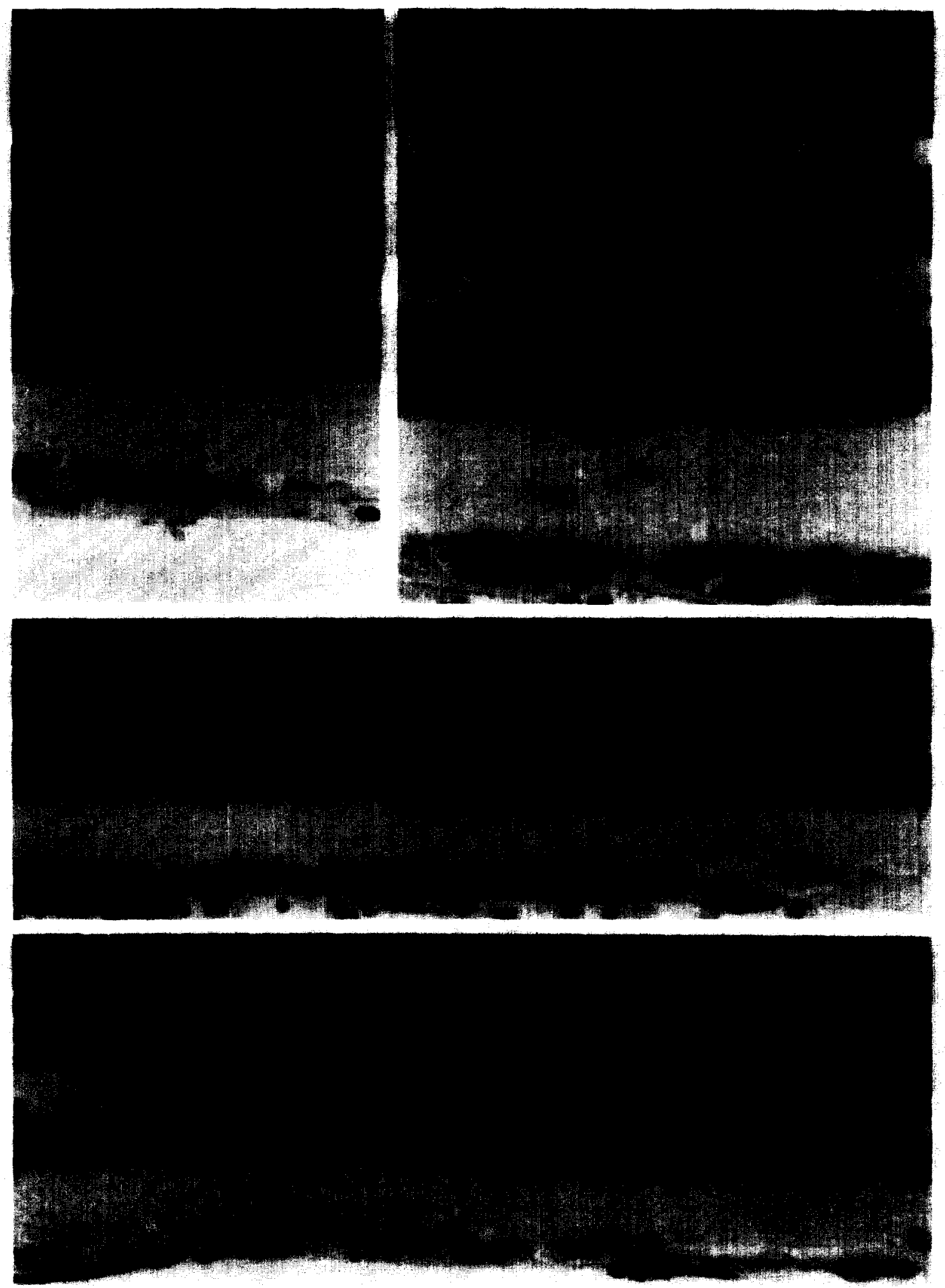

Fig. 1. A: radial methacrylate section of an untreated retina. B: retina 12 days after injection of 6 OHDA/TM. Note obvious loss of rod (arrowheads), but not cone (open arrows) nuclei. Also notice the swollen appearance of the retina and the prominent Müller cell nuclei (long, solid arrows) and processes (short, solid arrows) compared to untreated retina in A. C: same retina as in B showing homogeneous loss of rods. D: another retina treated as in B showing non-homogeneous loss of rods. on, outer nuclear layer; in, inner nuclear layer; gc, ganglion cell layer. $\mathrm{Bar}=10 \mu \mathrm{m}(\mathrm{A}, \mathrm{B}), 25 \mu \mathrm{m}(\mathrm{C}, \mathrm{D})$. 
Rods

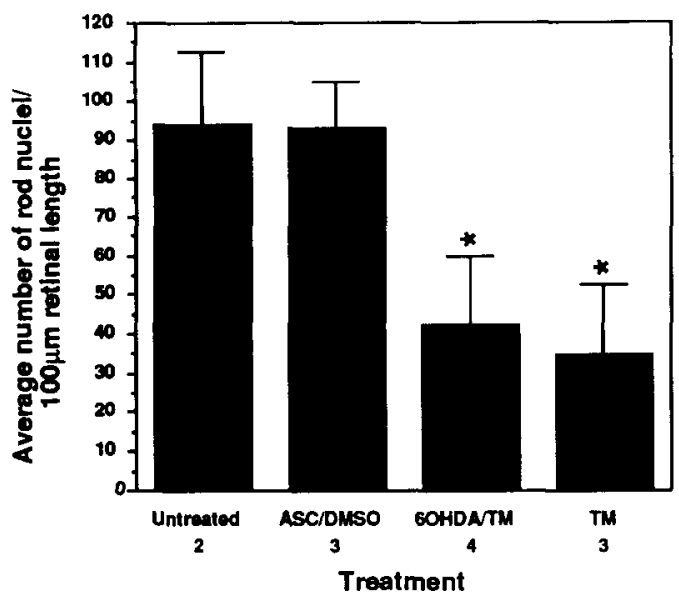

\section{Other Retinal Neurons}

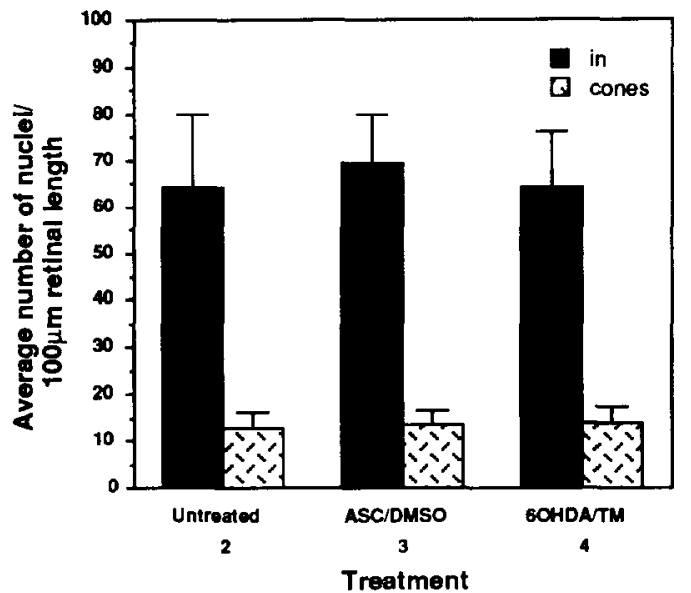

Fig. 2. Nuclear counts (see Materials and Methods) from radial methacrylate sections (4 per retina) of retinas from fish 12 days after the treatment indicated on the abscissa. The * indicates a significant difference in nuclear counts compared to untreated control retinas $(P<0.01)$. The error bars indicate one S.D. The number of retinas examined in each treatment group is indicated on abscissa. A: rod nuclear counts. B: INL. (in) and cone nuclear counts.
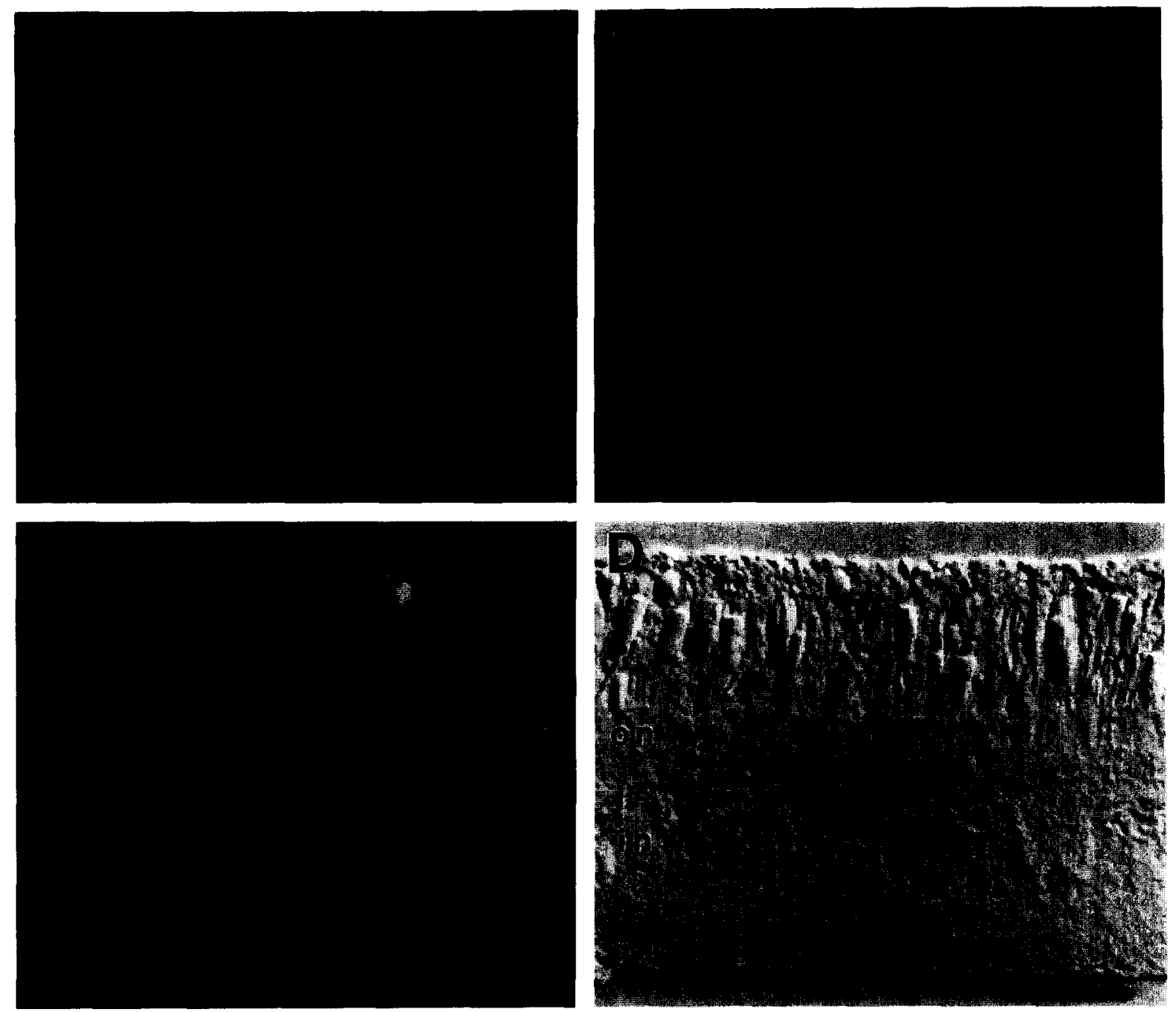

Fig. 3. A,B: whole mount preparations labeled with an anti-BUdR monoclonal antibody and focussed at the level of the ONL. A: retina 38 days after injection of 6OHDA/TM. Note abundance of BUdR + nuclei. B: retina 38 days after injection of 6 OHDA/DMSO. Only a few BUdR + nuclei (arrowheads) are in the plane of focus. C: radial frozen section of retina in A. Virtually all BUdR + nuclei are photoreceptors, except an occasional BUdR + nucleus in the vascular layer (arrowhead). Arrow indicates fluorescent debris. D: same section as retina in $\mathrm{C}$, viewed with

Nomarski optics. Abbreviations as in Fig. 1. Bar $=25 \mu \mathrm{m}$. 
cones, and INL nuclei were counted per $80 \mu \mathrm{m}$ retinal length (data were not corrected for shrinkage). Since a statistically significant difference was not found in the number of rod nuclei in dorsal versus ventral retina in any treatment group, data were pooled from dorsal and ventral retina. Data were analyzed using the one factor analysis of variance (ANOVA) and the post-hoc Sheffe $F$-test.

\section{Cryosections}

To determine whether an increase in rod photoreceptor production occurred after TM injection, the area with the maximum number of BUdR-labeled rod nuclei ( 1 area per section, 8-10 sections/ retina) was determined by inspection of RET1 /BUdR-labeled radial cryosections after TM (right eyes) or DMSO (left eyes) injection. These areas were centered in the field of view at $320 \times$ and all BUdR-labeled rods were counted in a $100 \mu \mathrm{m}$ length of retina. Data were analyzed using the unpaired Student's $t$-test.

\section{RESULTS}

Intraocular injection of TM selectively destroys rod photoreceptors in goldfish retina

Twelve days after 6OHDA/TM injection, rod loss was uniform across some retinas (Fig. 1B,C), while in others the damage was patchy, with some areas reduced to a single sparsely distributed row of rod nuclei and other areas appearing undamaged with approximately 3 rows of rod nuclei (Fig. 1D). This interretinal variability may be due to heterogeneity in intraretinal diffusion of the TM or leakage of drug from the injection site. In regions where rod loss was maximal, rod density in 6OHDA/TM injected retinas was on average $45 \%$ of untreated control values (Fig. 2A). No significant difference in density of rods was found between 6OHDA/TM and TM-injected retinas (Fig. $2 \mathrm{~A}$ ), suggesting that no drug interactions occurred. No significant difference in rod density was found between ASC/DMSO-injected and untreated retinas (Fig. 2A). At the dose used, the effect of TM was rod-specific since densities of cone and INL nuclei were not significantly different in untreated, ASC/DMSO and 6OHDA/TM-injected retinas (Fig. 2B). This was not the expected result, since TM has been shown in species other than the goldfish to destroy both rods and cones ${ }^{1,13,15}$. In the goldfish, Negishi and colleagues $^{33}$ suggest that intraocular injection of TM destroys mostly photoreceptors (rods and possibly cones), but the damage may spread to the inner retina and therefore the lesion may not be selective (we estimate the intraocular concentration they used was $0.03 \mathrm{mg}$ / $\mathrm{ml}$, which is $50 \%$ greater than ours). Garcia et al. ${ }^{15}$ have also demonstrated in rabbit and primate retina that high doses of TM can destroy cells in the inner retina in addition to photoreceptors. Our preliminary results using a higher dose of TM $(0.04 \mathrm{mg} / \mathrm{ml})$ support the idea that cones in addition to inner retinal neurons may be lost (Braisted and Raymond, unpublished observations).

Rod photoreceptor production is stimulated after destruction of rods with intraocular injection of TM

A large number of BUdR + nuclei were found in the ONL of retinas 38 days after injection of 6OHDA/

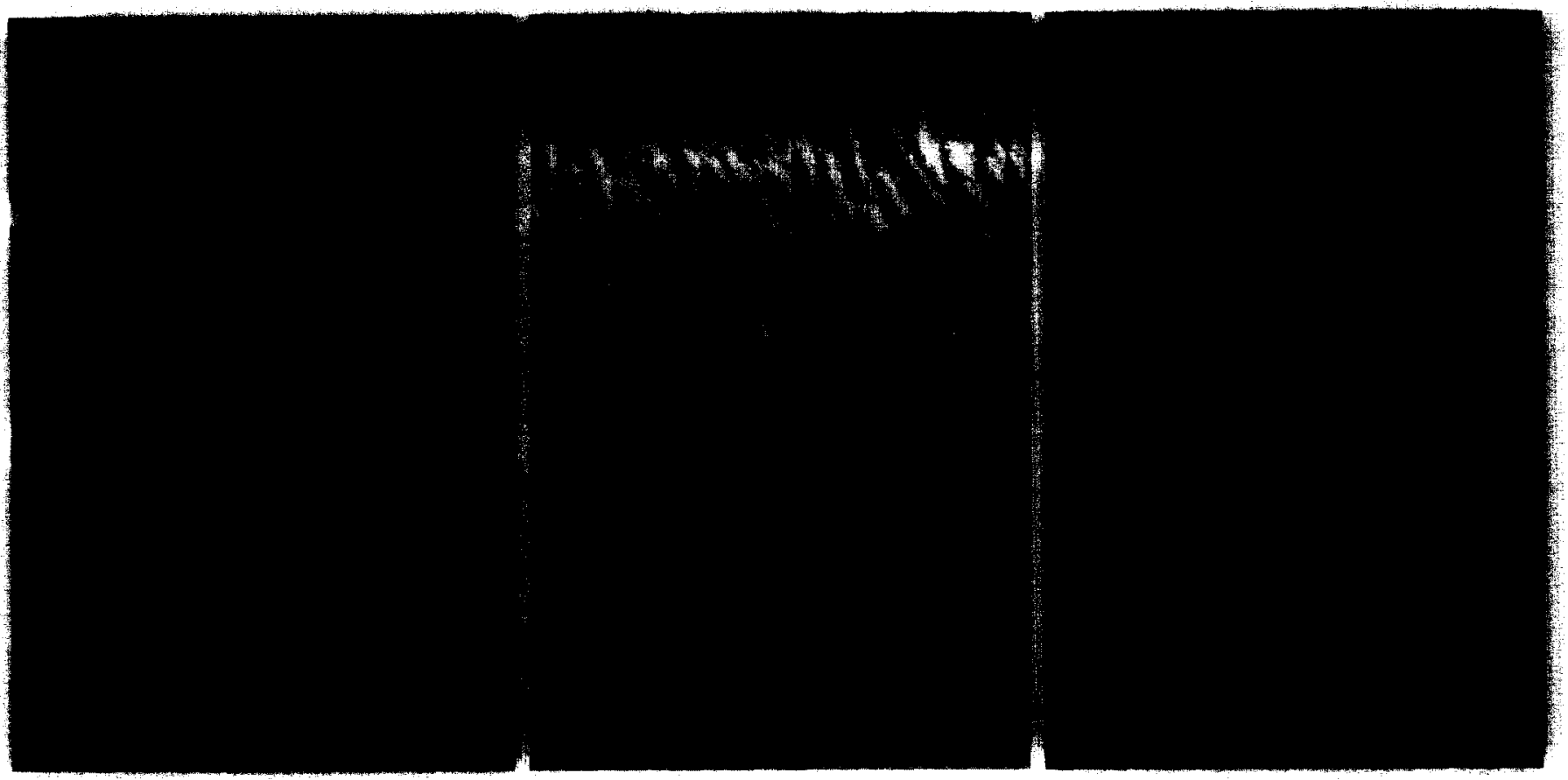

Fig. 4. Radial cryosection of a retina 38 days after injection of TM and 15 days after the last of 4 injections of BUdR, double-immunostained with mouse RET1 monoclonal antibody (A) and rat anti-BUdR monoclonal antibody (C). B: same field of view as in A and C, viewed with Nomarski optics. Note that none of the BUdR + nuclei in the ONL double-label with RET1, and we therefore conclude that they are rods. Arrowhead indicates BUdR + nucleus in the vascular layer. $c$, layer of cone nuclei; $r$, layer of rod nuclei; other abbreviations as in Fig. 1 . Bar $=25 \mu \mathrm{m}$. 


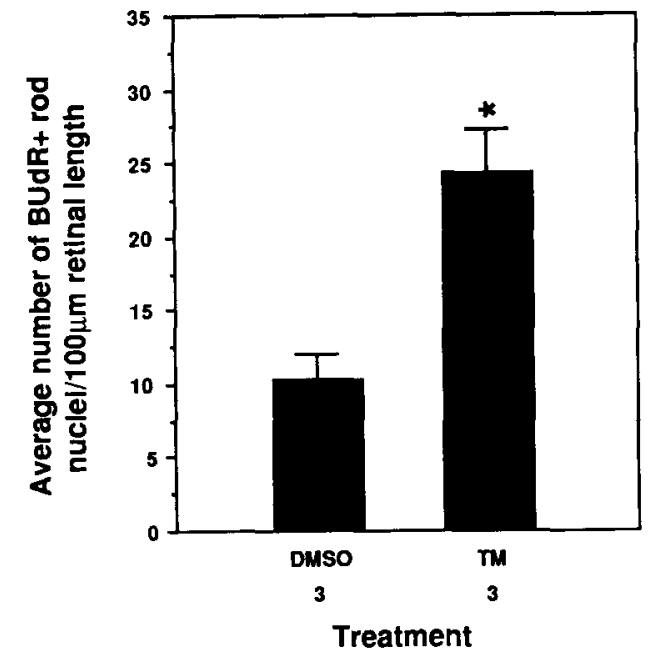

Fig. 5. Nuclear counts (see Materials and Methods) from radial frozen sections of retinas 38 days after injection of DMSO or TM. The ${ }^{*}$ indicates a significant difference in the number BUdR + nuclei compared to DMSO injected control retinas $(P<0.01)$. The error bars indicate one S.D. The number of retinas examined in each treatment group is indicated on abscissa.

TM (Fig. 3A) compared to 6OHDA/DMSO-injected control retinas (Fig. 3B). Since it was difficult to distinguish cone from rod nuclei in these whole mount preparations, some whole mounts were frozen and $3-\mu \mathrm{m}$ radial cryosections were examined. All the BUdR + nuclei were found in the ONL (Fig. 3C,D), but we could not be absolutely certain that all the BUdR + nuclei belonged to rods and not to cones for the following reasons: (1) unstained rod and cone nuclei could not be distinguished with differential inter- ference contrast optics since the photoreceptor nuclei were compressed in cryosectioned whole mounts; (2) rod and cone nuclei could not be stained with fluorescent nuclear stains such as DAPI or Hoechst, because the DNA was damaged in the acid denaturation step required for BUdR immunocytochemistry; (3) we have no antibodies that label rod nuclei or cell bodies and (4) the antigen recognized by our cone antibody (RET1) was destroyed in the acid denaturation step.

To overcome these difficulties, whole eyes from another group of fish 38 days after injection of TM (right eyes) or DMSO (left eyes) were cryosectioned and processed for double-label immunocytochemistry with RET1 and anti-BUdR monoclonal antibodies. No $\mathrm{RET} 1+/ \mathrm{BUdR}+$ (cone) nuclei were found in either TM- or DMSO-injected retinas, suggesting that all the BUdR + nuclei in the ONL are indeed rods (Fig. 4). A 2.4-fold increase in the number of BUdR + rod nuclei was found in TM-injected retinas compared to DMSO-injected control retinas (Fig. 5), suggesting that rod precursors up-regulate production of rods to compensate for the destruction of rods caused by TM.

\section{Rare dopaminergic neurons survive 6OHDA}

Dopaminergic interplexiform cells (DA IPCs), which are the only tyrosine hydroxylase-immunoreactive $\mathrm{TH}$ $+)$ cells in the goldfish retina ${ }^{8,38}$, have large cell bodies $(\sim 11 \mu \mathrm{m})$ located in the inner part of the INL (amacrine cell layer) and robust processes (Fig. 6B) that synapse in both the inner and outer plexiform layers. These cells are sparsely distributed (Fig. 6A),
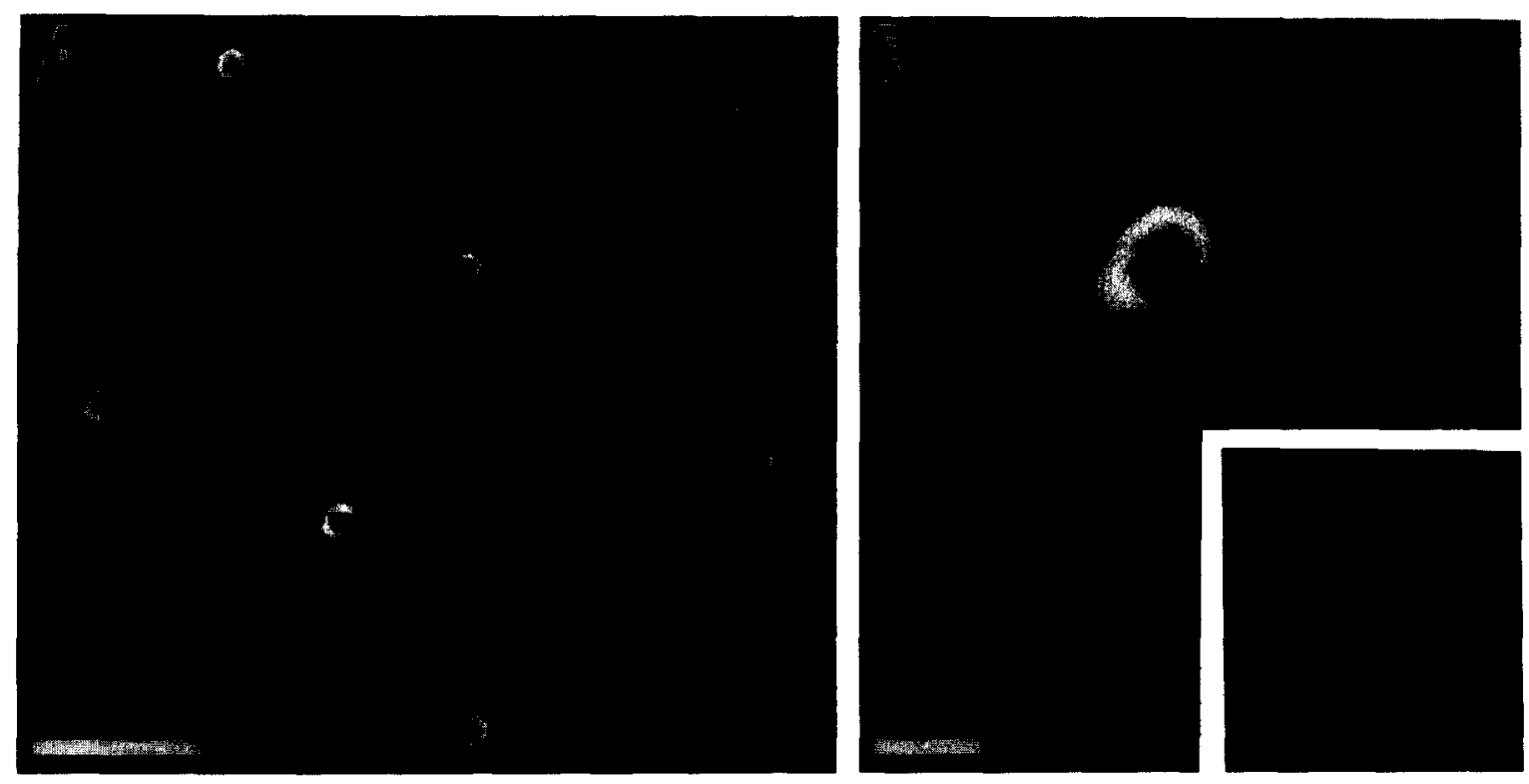

Fig. 6. A: field of DA IPCs labeled with an anti-TH monoclonal antibody in a whole mount preparation of an untreated retina. B: higher magnification showing $\mathrm{TH}$-immunoreactive $(\mathrm{TH}+)$ processes (arrowheads) originating from $\mathrm{TH}+$ cell body. $\mathrm{B}$ (inset): weakly immunoreactive $\mathrm{TH}+$ cell body of rare surviving DA IPC in central portion of another retina 38 days after injection of 6 OHDA $/$ TM. Bar $=50 \mu \mathrm{m}(\mathrm{A}), 10 \mu \mathrm{m}$ (B and inset) 


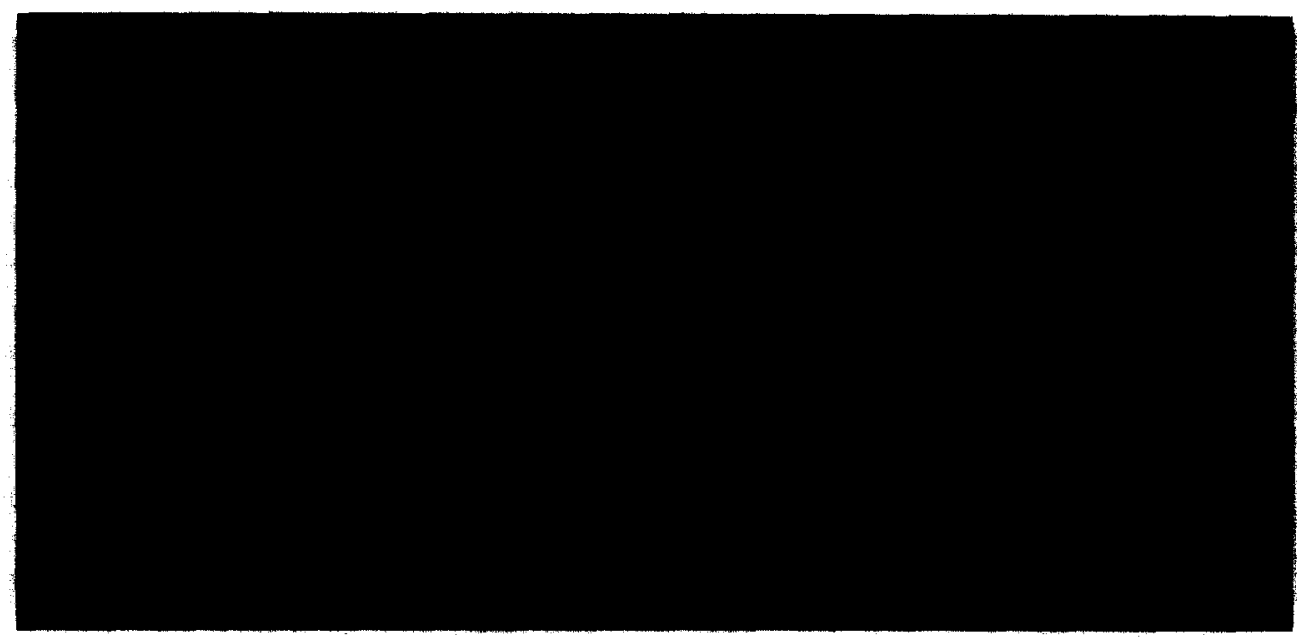

Fig. 7. Field of regenerated DA IPCs labeled with an anti-TH monoclonal antibody in a whole mount preparation of a retina 38 days after intraocular injection of $9 \mathrm{mg} / \mathrm{ml} 6$ OHDA (estimated intraocular concentration $0.42 \mathrm{mg} / \mathrm{ml}$ or $2.1 \mathrm{mM}$ ) in $0.9 \%$ saline $+3 \mathrm{mg} / \mathrm{ml} \mathrm{sodium}$ ascorbate on 2 consecutive days. This dose causes non-specific damage and triggers a regenerative response (Braisted and Raymond, 1992 and unpublished observations). Note both in-focus (open arrows) and out-of-focus (solid arrows) cell bodies as well as $\mathrm{TH}+$ processes (arrowheads) originating from $\mathrm{TH}+$ cell bodies. Bar $=25 \mu \mathrm{m}$.

with an approximate average density of 200 cells $/ \mathrm{mm}^{2}$ (refs. 32, 35).

In 5 of 8 retinas examined 38 days after injection of
6OHDA / DMSO or 6OHDA/TM, an extremely small number $(<1 \%$ of total number of $\mathrm{TH}+$ cells in untreated retinas) of weakly immunoreactive, $\mathrm{TH}+$ cell

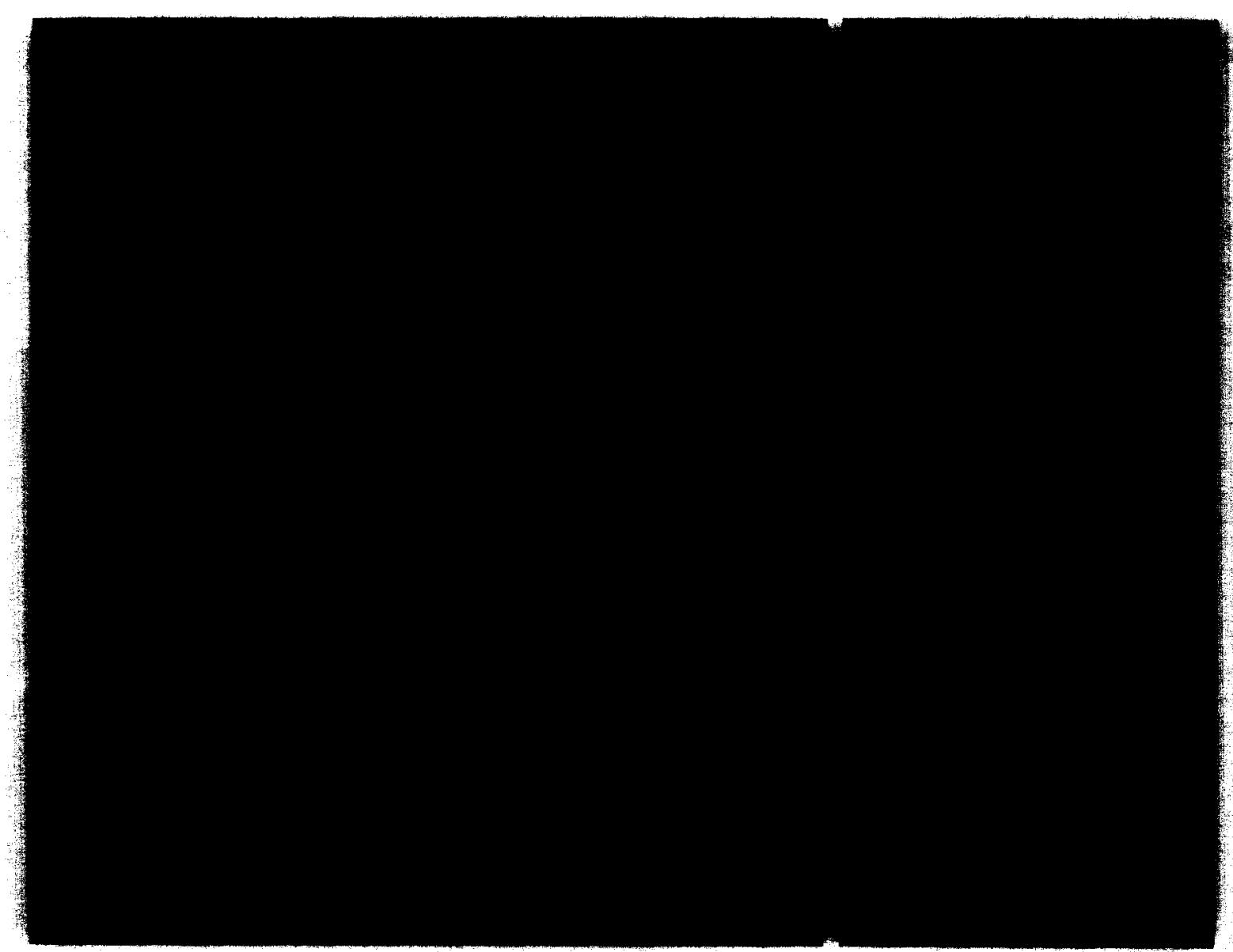

Fig. 8. DA IPCs labeled with an anti-TH monoclonal antibody in whole mount preparations. A: 420 days after injection of $60 H D A / D S M O$. Many intensely immunoreactive $\mathrm{TH}+$ cell bodies and processes (arrowheads) are found in the growth zone as part of ongoing process of retinal growth. B: higher magnification of DA IPC indicated by arrow in A. Note presence of long TH+ process (arrowhead) growing into dopamine-free central retina (toward bottom of photo). Bars $=50 \mu \mathrm{m}(\mathrm{A}), 25 \mu \mathrm{m}(\mathrm{B})$ 
TABLE II

Number of $T H+D A I P C$ s surviving $6 O H D A$

Each value represents the total number of weakly $\mathrm{TH}+$ cells in the central portion of one retina. Since there are $\sim 3000$ DA IPCs per untreated retina, at most $<1 \%(25 / 3000)$ survive 6 OHDA.

\begin{tabular}{|c|c|c|c|}
\hline \multicolumn{3}{|c|}{$60 H D A / D M S O$} & \multirow{2}{*}{$\frac{60 H D A / T M}{38 \text { days }}$} \\
\hline 7 days & 38 days & $\overline{420 \text { days }}$ & \\
\hline 0 & 0 & 0 & 0 \\
\hline 2 & 5 & 0 & 0 \\
\hline 1 & & 2 & 8 \\
\hline 1 & & $3 *$ & 15 \\
\hline 4 & & & 19 \\
\hline 8 & & & 22 \\
\hline
\end{tabular}

13

* 2 of the 3 DA IPCs in this retina have apparently recovered, since they possess intensely $\mathrm{TH}+$ cell bodies and processes.

bodies were found in central retina (Table II, inset Fig. 6B). Similar faintly stained cells were also present in 7 of 8 control retinas examined 7 days after 6OHDA/ DMSO injection (Table II) at a time when regeneration of $\mathrm{TH}+$ cells should not have occurred ${ }^{4}$. These cells showed the following characteristics: (1) uniform cell body diameters $(\sim 11 \mu \mathrm{m})$, (2) widely spaced cell bodies ( $>100 \mu \mathrm{m}$ between nearest neighbors), (3) cell bodies in the same focal plane when viewed in a whole mount preparation, and (4) no $\mathrm{TH}+$ processes. In contrast, regenerated DA IPCs as visualized in whole mounts by us ${ }^{4}$ and as reported by others ${ }^{36}$ showed very different characteristics including: (1) variable cell body diameters, (2) clumped distribution of cell bodies (occasionally lying adjacent to one another), (3) cell bodies at various depths when viewed in whole mounts, and (4) $\mathrm{TH}+$ processes (Fig. 7). We therefore believe that these rare, weakly $\mathrm{TH}+$ cells were DA IPCs that survived 6OHDA treatment.

To determine the fate of these surviving DA IPCs, 4 retinas were examined 420 days after 6 OHDA/DMSO injection. In 1 of these retinas, 2 weakly immunoreactive $\mathrm{TH}+$ cells persisted in central retina, in 1 retina 1 weakly immunoreactive $\mathrm{TH}+$ cell persisted in central retina along with 2 cells that apparently recovered (they had intensely immunoreactive, $\mathrm{TH}+$ cell bodies and processes), and in 2 of the 4 retinas no $\mathrm{TH}+$ cells were found in central retina (Table II). In all 4 retinas intensely immunoreactive $\mathrm{TH}+$ cells were found in the most peripheral retina (Fig. $8 \mathrm{~A}$ ), as discussed below, and represent a growth process, not regeneration.

Dopaminergic neurons do not regenerate if they are selectively destroyed along with rods

Many intensely immunoreactive, $\mathrm{TH}+$ cell bodies and processes were found in untreated retinas (Fig.
6A), but 38 days after injection of 6OHDA/DMSO or 6OHDA/TM, intense $\mathrm{TH}+$ cells were found only in the most peripheral retina (Fig. 8A). These represent newly added DA IPCs generated by the germinal zone as part of an ongoing process of retinal growth ${ }^{34}$. As described by others ${ }^{34}$, the TH + DA IPCs in the new retina produced by the germinal zone after 6OHDA injection had long processes extending into the DA IPC-free central retina (Fig. 8B). In contrast, processes of DA IPCs in the far periphery of untreated retinas tended to extend parallel to the retinal margin ${ }^{34}$. Very rare, weakly immunoreactive $\mathrm{TH}+$ cell bodies were found in some retinas after either 6OHDA/TM or 6OHDA/DMSO injection, but we believe that these represent DA IPCs that survived 6OHDA as discussed above. No regenerated $(\mathrm{TH}+/ \mathrm{BUdR}+)$ DA IPCs were found in 6OHDA/TM- $(n=6)$ or 6OHDA/ DMSO-injected $(n=6)$ retinas.

\section{DISCUSSION}

These data suggest that rod precursors in the ONL do not alter their normal pathway of development to replace DA IPCs in the INL when damage to the ONL is limited to destruction of rods. Although TM has been reported to kill both rods and cones in species other than the goldfish ${ }^{1,13,15}$, results from the present study indicate that only rods are killed when TM is injected intraocularly at this dose $(0.02 \mathrm{mg} / \mathrm{ml}$, estimated intraocular concentration) in goldfish. Since we did not examine serial sections through entire retinas, we cannot be absolutely certain that no cone loss occurred. However, since the analysis was confined to the most damaged regions of retina within individual sections (i.e. areas with most rod loss), if cones were destroyed, this loss must have been minimal. In contrast to the results reported here, Negishi and colleagues ${ }^{33}$ recently demonstrated that TM destroys rods and possibly cones when injected intraocularly in the goldfish (we estimate their intraocular concentration to be $0.03 \mathrm{mg} / \mathrm{ml}$ ), and it may destroy some cells in inner retinal layers as well ${ }^{33}$. Unfortunately, no comparison of nuclear densities before and after TM injection was given in the previous study, either for photoreceptors or inner retinal neurons. Although the authors convincingly demonstrated a decrease in cone height after administration of TM, one cannot eliminate the possibility that the damaged cones recovered, and did not regenerate.

Although we believe that the present results suggest that selective loss of rods and dopaminergic neurons is insufficient to trigger an alteration of rod precursor cell fate, we cannot eliminate the possibility that TM 
interferes with the processes critical for the regeneration of dopaminergic neurons. However, (see below) the cells likely to be responsible for regeneration (the rod precursors) are not destroyed, since they continue to divide and produce new rod photoreceptors after TM injection. In addition, the signals necessary for dopaminergic neuron production per se are not abolished after TM injection, since new dopaminergic neurons continue to be produced by the germinal zone as part of the ongoing process of retinal growth. An alternative explanation for the failure of dopaminergic neurons to regenerate in this paradigm is that signals mediated by cell contact may be required and because rod precursors are located in the ONL, they may not be able to detect the loss of a single cell type in the inner retina, when retinal lamination remains intact.

In a previous study ${ }^{4}$ we found that DA IPCs were completely ablated 7 days after 2 intraocular injections of $0.14 \mathrm{mg} / \mathrm{ml}$ 6OHDA, the same dose used in this study. In our earlier study, the presence of DA IPCs was determined by examining radial sections labeled with an anti-TH polyclonal antibody (EugeneTech, Allentown, $\mathrm{NJ}$ ) visualized by indirect immunofluorescence. In the present study, however, we found rare DA IPCs $(<1 \%$ of the total population) that survived in 14 of 20 retinas examined $\leqslant 420$ days after 6OHDA/DMSO or 6OHDA/TM injection. The apparent discrepancy in these results is likely due to the improved sensitivity of the detection methods used in the present paper: entire retinas were examined in whole mount preparations, a more sensitive anti- $\mathrm{TH}$ monoclonal antibody was used, and the fluorescent signal was amplified with the biotin/avidin secondary antibody system. It is also possible that the DMSO interfered with the ability of 6OHDA to destroy DA IPCs. However, since no regenerated DA IPCs were found in any retina, either with or without surviving DA IPCs, their presence must not have been an impediment to regeneration, and their absence must not have been sufficient to trigger it.

The fate of the surviving, but weakly immunoreactive $\mathrm{TH}+\mathrm{DA}$ IPCs varied among retinas examined 420 days after 6OHDA/DMSO injection. We expected that they were damaged and would all eventually die or recover. We were therefore surprised to find that a few weakly $\mathrm{TH}+$ cell bodies without processes persisted in 2 of 4 retinas examined. Why these cells remained in an apparently abnormal state remains unexplained.

Results from the present study also demonstrated that rod precursors are able to respond to a decrease in rod density by increasing the rate of production of rods, a result that is not surprising since regulation of rod density is a feature of normal and abnormal ${ }^{4.5}$ retinal growth. The density of rods is held approximately constant in adult goldfish ${ }^{42}$ despite large variations in individual growth rates ${ }^{20,22}$. The implication is that mitotic activity in rod precursors must be stimulated by a decrease in rod density (perhaps due to retinal stretching during growth ${ }^{45}$ ), such that an appropriate number of rods is produced to keep the density of rods constant. Alternatively, mitogens released by phagocytic microglia or other vascular cells infiltrating in response to destruction of rods following TM injection may alter the rate of rod production. Earlier studies suggested that proliferation of rod precursors may be modulated by mitogens released following lesions of optic nerve $\mathrm{e}^{16}$ or associated brain regions ${ }^{39}$.

The specific molecular signals that regulate the rate of rod production and the steps in the cell cycle at which regulation occurs are not yet known. The increase in number of proliferating rod precursors seen following injury could be a result of one or more different mechanisms. It is possible that the cell cycle length is shortened, or alternatively, a quiescent population of rod precursors might re-enter the mitotic cycle when the density of rods falls below a certain threshold. In an attempt to reveal such a putative quiescent population of rod precursors, we injected the anti-proliferative agent 5-fluorouracil into adult goldfish eyes to kill actively proliferating rod precursors, then stimulated regeneration with high doses of $6 \mathrm{OHDA}^{3}$. Unfortunately, the drug failed to kill $100 \%$ of the dividing rod precursors, and therefore the issue of whether quiescent rod precursors, or other neuroepithelial cells, exist in central differentiated regions of adult goldfish retina remains unsolved.

Our search for the cellular signal that causes a rod precursor to produce neurons other than rods continues. One hypothesis currently being investigated is that an absence of cones triggers an alteration in rod precursor fate. This idea would be consistent with the known sequence of retinal neurogenesis: rods are produced late in development, only after a complete monolayer of cones has formed ${ }^{43}$. Since we were unable to specifically ablate cones in addition to rods with TM (without damaging the inner retinal layers), we are currently employing a new approach, laser ablation, to selectively destroy both cone and rod photoreceptors. By combining laser ablation of photoreceptors with chemical ablation of dopaminergic neurons with low doses of 6OHDA, we are attempting to stimulate regeneration of DA IPCs.

Acknowledgements. We wish to thank Linda K. Barthel for expert technical assistance and Dr. Steven S. Easter, Jr. for providing a 
translation from the Italian of the two Lombardo papers ${ }^{28,29}$. This research was supported by NIH R01 EY04318 and NIH F31 MH10220. Pamela A. Raymond has published previously as P.R. Johns.

\section{REFERENCES}

1 Anderson, D.H., Williams, D.S., Neitz, J., Fariss, R.N, and Fliesler, S.J., Tunicamycin-induced degeneration in cone photoreceptors, Vis. Neurosci, 1 (1988) 153-158.

2 Barthel, L.K. and Raymond, P.A., Improved method for obtaining $3-\mu \mathrm{m}$ cryosections for immunocytochemistry, J. Histochem. Cytochem., 38 (1990) 1383-1388.

3 Braisted, J.E. and Raymond, P.A., 5-Fluorouracil inhibits rod precursor proliferation in goldfish retina, Intest. Ophthalmol. Vis. Sci., Suppl. 33 (1992) 1061.

4 Braisted, J.E. and Raymond, P.A., Regeneration of dopaminergic neurons in goldfish retina, Decelopment, 114 (1992) 913-919.

5 Cohen, G. and Heikkila, R.E., The generation of hydrogen peroxide, superoxide radical, and hyroxyl radical by 6-hydroxydopamine, dialuric acid, and related cytotoxic agents, J. Biol. Chem., 249 (1974) 2447-2454.

6 Coulombre, J.L. and Coulombre, A.J., Regeneration of neural retina from the pigmented epithelium in the chick embryo, Det. Biol., 12 (1965) 79-92.

7 Coulombre, J.L. and Coulombre, A.J., Influence of mouse neural retina on regeneration of chick neural retina from chick embryonic pigmented epithelium, Nature, 228 (1970) 559-560.

8 Dowling, J.E. and Ehinger, B., The interplexiform cell system. I. Synapses of the dopaminergic neurons of the goldfish retina, Proc. R. Soc. London B, 201 (1978) 7-26.

9 Easter Jr., S.S., Johns, P.R. and Baumann, L.R., Growth of the adult goldfish eye. I. Optics, Vis. Res., 17 (1977) 469-477.

10 Elbein, A.D., Inhibitors of the biosynthesis and processing of $\mathrm{N}$-linked oligosaccharides, CRC Crit. Rev. Biochem., 16 (1984) $21-49$.

11 Fernald, R.D., Retinal rod neurogenesis. In B.L. Finlay and D.R. Sengelaub (Eds.), Development of the Vertebrate Retina, Plenum, New York, 1988, pp. 31-42.

12 Fliesler, S.J. and Basinger, S.F., Tunicamycin blocks the incorporation of opsin into retinal rod outer segment membranes, Proc. Natl. Acad. Sci. USA, 82 (1985) 1116-1120.

13 Fliesler, S.J., Rapp, L.M. and Hollyfield, J.G., Photoreceptorspecific degeneration caused by tunicamycin, Nature, 311 (1984) 575-577.

14 Fliesler, S.J., Rayborn, M.E. and Hollyfield, J.B., Membrane morphogenesis in retinal rod outer segments: inhibition by tunicamycin, J. Cell Biol., 100 (1985) 574-587.

15 Garcia, C.A., Chu, H.H., Matheny, J.L., Chu, L., Zhuang, S., Venger, C. and Fliesler, S.J., Tunicamycin-induced retinal degeneration in rabbit and primate retinas, Invest. Ophthalmol. Vis. Sci., Suppl. 26 (1985) 34.

16 Henken, D.B. and Yoon, M.G., Optic nerve crush modulates proliferation of rod precursor cells in the goldfish retina, Brain Res., 501 (1989) 247-259.

17 Hitchcock, P.F., Exclusionary dendritic interactions in the retina of the goldfish, Development, 106 (1989) 589-598.

18 Hitchcock, P.F., Lindsey, K.J., Easter Jr., S.S., Mangione-Smith, $\mathrm{R}$. and Dwyer Jones, D., Local regeneration in the retina of the goldfish, J. Neurobiol., 23 (1992) 187-203.

19 Hitchcock, P.F. and Raymond, P.A., Retinal regeneration, Trends Neurosci, 15 (1992) 103-108.

20 Johns, P.R., Growth of the adult goldfish retina, Ph.D. thesis, University of Michigan, 1976.

21 Johns, P.R., The formation of photoreceptors in the growing retinas of larval and adult goldfish, J. Neurosci., 2 (1982) 179-198.

22 Johns, P.R. and Easter Jr., S.S., Growth of the adult goldfish eye. II. Increase in retinal cell number, J. Comp. Neurol., 176 (1977) 331-342.

23 Johns, P.R. and Fernald, R.D., Genesis of rods in the retina of teleost fish, Nature, 293 (1981) 141-142.
24 Johnson, B.D. and Araujo, G.M., A simple method of reducing the fading of immunofluorescence during microscopy, $J . \mathrm{Im}$ munol. Methods, 43 (1981) 349-350).

25 Jonsson, G. and Sachs, C., Actions of 6-hydroxydopamine quinones on catecholamine neurons, J. Neurochem., 25 (1975) $509-516$

26 Keefe, J.R., An analysis of Urodelian retinal regeneration. I. Studies of the cellular source of retinal regeneration in Notophthalmus tiridescens utilizing ${ }^{3} \mathrm{H}$-thymidine and colchicine, J. Exp. Zool., 184 (1973) 207-232.

27 Keefe, J.R., An analysis of Urodelian retinal regeneration: IV. Studies of the cellular source of retinal regeneration in Triturus cristatus carnifex using ${ }^{3} \mathrm{H}$-thymidine, I. Lxp. Zool., 184 (1973) 239-258.

28 Lombardo, F., The regeneration of the retina in the adult teleost, Accad. Lincei-Rend. Cont. Sci. Fis. Mat. e. Nat. (in Italian), 45 (1968) 631-635.

29 Lombardo, F., Time course and localization of mitoses during the regeneration of the retina of an adult teleost. Accad. Lincei-Rend. Cont. Sci. Fis. Mat. e. Nat. (in Italian), 53 (1972) 323-327.

30 Maier, W. and Wolburg, H., Regeneration of the goldfish retina after exposure to different doses of ouabain. Cell Tiss. Res.. 2012 (1979) 99-118.

31 Müller, H., Bau und Wachstum der Netzhaut des Guppy (Lebistes reticulatus), Zool. Jahrb. Aht. Allg. Zool. Physiol. Tiere, 63 (1952) $275-324$

32 Negishi, K., Density of retinal catecholamine-accumulating cells in different-sized goldfish. Exp. Eve Res., 33 (1981) 223-232.

33 Negishi, K., Sugawara, K., Shinagawa, S.. Teranishi. T., Kuo, C.-H. and Takasaki, Y., Induction of immunoreactive proliferating cell nuclear antigen (PCNA) in goldfish retina following intravitreal injection with tunicamycin, Der. Brain Res., 63 (1991) $71-83$.

34 Negishi, K.. Teranishi. T. and Kato. S.. New dopaminergic and indoleamine-accumulating cells in the growth zone of goldfish retinas after neurotoxic destruction, Science, 216 (1982) 747-749.

35 Negishi, K., Teranishi, T. and Kato, S., Growth rate of a peripheral annulus defined by neurotoxic destruction in the goldfish retina, Dev: Brain Res., 20 (1985) 291-295.

36 Negishi, K., Teranishi, T., Kato, S. and Nakamura, Y., Paradoxical induction of dopaminergic cells following intravitreal injection of high doses of 6-hydroxydopamine in juvenile carp retina, Det: Brain Res., 33 (1987) 67-79.

37 Negishi, K., Teranishi, T., Kato, S. and Nakamura, Y., Immunohistochemical and autoradiographic studies on retinal regeneration in teleost fish, Neurosci. Res., Suppl. 8 (1988) S43-47.

38 Negishi, K., Teranishi, T. and Kato, S., The dopamine system of the teleost fish retina, Prog. Retinal Res. . 9 (1990) 1-48.

39 Owusu-Yaw, V., Kyle, A.L. and Stell, W.K., Effects of lesions of the optic nerve, optic tectum and nervus terminalis on rod precursor proliferation in the goldfish retina, Brain Res., 576 (1992) 220-230.

40 Park, C.M. and Hollenberg, M.J., Basic fibroblast growth factor induces retinal regeneration, in vivo, Der. Biol., 134 (1989) 201 205.

41 Plantner, J.J., Poncz, L. and Kean, E.L., Effect of tunicamycin on the glycosylation of rhodopsin, Arch. Biochem. Biophys. 201 (1980) $527-532$

42 Powers, M.K., Bassi, C.J. Rone, L.A. and Raymond, P.A., Visual detection by the rod system in goldfish of different sizes. Vis. Res., 28 (1988) 211-221.

43 Raymond, P.A., The unique origin of rod photoreceptors in the teleost retina, Trends Neurosci., 8 (1985) 12-17.

44 Raymond, P.A., Retinal regeneration in teleost fish. In E. Rubel (Ed.), Regeneration of Vertebrate Sensory Cells, Ciba Fnd. Symp. Vol. 60, Wiley, Chichester, 1991, pp. 171-191.

45 Raymond, P.A., Hitchcock, P.F. and Palopoli, M.F., Neuronal cell proliferation and ocular enlargement in the black moor goldfish, J. Comp. Neurol, 276 (1988) 231-238.

46 Raymond, P.A., Reifler, M.J, and Rivlin, P.K., Regeneration of goldfish retina: rod precursors are a likely source of regenerated cells, J. Neurobiol., 19 (1988) 431-463. 
47 Raymond, P.A. and Rivlin, P.K., Germinal cells in the goldfish retina that produce rod photoreceptors, Del: Biol., 122 (1987) 120-138.

48 Reh, T.A. and Nagy, T., A possible role for the vascular membrane in retinal regeneration in Rana catesbienna tadpoles, Det: Biol., 122 (1987) 471-482.

49 Schutte, B., Reynders, M.M., Bosman, E.T. and Blijham, G.H., Studies with anti-bromodeoxyuridine antibodies. II. Simultaneous immunocytochemical detection of antigen expression and DNA synthesis by in vivo labeling of mouse intestinal mucosa, $J$. Histochem. Cytochem., 35 (1987) 371-374.
50) Schwarz, R.T, and Datema, R.. The lipid intermediate pathway of protein glycosylation and its inhibitors; the biological significance of protein-bound carbohydrates, Adl: Carbohyd. Chem. Biochem., 40 (1982) 287-379.

51 Stone, L.S., The role of retinal pigmented cells in regenerating neural retinae of adult salamander eyes, J. Exp. Neurol., 113 (1950) 9-31.

52 Wagner, E. and Raymond, P.A., Müller glial cells of the goldfish retina are phagocytic in vitro but not in vivo, Exp. Eye Res., 53 (1991) 583-589. 